\title{
OPTIMASI TITIK INTERKONEKSI DISTRIBUTED GENER- ATION (PLTM MUARA) GUNA MEMINIMALKAN RUGI - RUGI DAYA MENGGUNAKAN METODE ARTIFICIAL BEE COLONY (ABC) PADA PENYULANG PANJI
}

\author{
I Made Arya Supartana ${ }^{1}$, Rukmi Sari Hartati ${ }^{2}$, I Wayan Sukerayasa ${ }^{3}$ \\ Program Studi Teknik Elektro, Fakultas Teknik, Universitas Udayana \\ Kampus Bukit Jimbaran, Bali, 80361 \\ Email: madearya.supartana@gmail.com
}

\begin{abstract}
Abstrak
Distributed Generatinon (DG) adalah pembakit Istrik kecil yang dapat meningkatkan keandalan, profil tegangan dan mengurangi rugi - rugi daya pada suatu jaringan distribusi. Lokasi interkoneksi DG yang kurang tepat, dapat meningkatkan terjadinya rugi - rugi daya. Salah satu cara yang dapat dilakukan untuk mengurangi rugi - rugi daya tersebut adalah dengan optimasi titik interkoneksi DG. Optimasi titik interkoneksi DG pada Penyulang Panji bertujuan untuk meminimalkan rugi - rugi daya, dimana nilai rugi - rugi daya awal yang terjadi sebesar 48,2 kW. Teknik optimasi yang digunakan adalah metode Artificial Bee Colony $(A B C)$, dengan hasil simulasi optimasi terdapat rugi - rugi sebesar 32,263 kW. Terjadi selisih penurunan rugi - rugi daya sebelum dan setelah optimasi sebesar 16,035 kW, atau terjadi penurunan rugi - rugi daya sebesar 33,2 \% dari rugi sebelumnya.
\end{abstract}

Kata kunci : Distributed Generation, Rugi-Rugi Daya, Artificial Bee colony, Optimasi

\begin{abstract}
Distributed Generation (DG) is a small power plant that can increase realibility, voltage profil, and reduce power losses in distribution network. DG interconnection locations that are less suitable can in/crease power losses. A possibility that can be done to reduce these power losses is by optimizing $D G$ interconnection points. Optimization of the $D G$ interconnection points on the feeder of Panji aims to minimize power losses, where the initial power losses occur at $48.2 \mathrm{~kW}$. Optimization technique is using the Artificial Bee Colony $(A B C)$ method with losses after simulation at $32.263 \mathrm{~kW}$. When compared with the conditions before and after optimization there is a difference in power losses of $16.035 \mathrm{~kW}$, to a decrease in power losses of $33.2 \%$ from the previous loss.
\end{abstract}

Keywords : Distributed Generation, Power Losses, Artificial Bee Colony, Optimization

\section{Pendahuluan}

Distributed Generation (DG) adalah pembangkit terdistribusi sekala kecil dengan memanfaatkan sumber energi non fosil atau terbarukan seperti sinar matahari, panas bumi, angin, air gelombang laut, arus laut, biomassa, dan biogas untuk menghasilkan daya listrik [1].

Kapasitas DG berbeda-beda dari 1 kW $10 \mathrm{MW}$, karena pembangkit ini disesuaikan dengan potensi yang ada di wilayah tersebut. Distributed Generation (DG) dapat memperbaiki drop tegangan, mengurangi rugi-rugi daya, meningkatkan keandalan, dan kualitas daya [2].
Pembangkit Listrik Tenaga Minihidro (PLTM) Muara telah dioperasikan untuk menambah suplai daya listrik pada penyulang Panji. Dengan adanya PLTM ini, penyulang Panji saat ini memiliki 2 suplai tenaga listrik yaitu dari GI Pemaron dan PLTM Muara. PLTM ini berlokasi di Desa Sambangan, Kecamatan Sukasada kabupaten Singaraja.

Kondisi eksisting dari DG (PLTM Muara) terinterkoneksi ke busbar 20 kV gardu SK 64 sebagai tambahan supplai daya pada penyulang Panji. Optimasi titik interkoneksi DG sebagai alternatif baru untuk meminimalkan rugirugi daya.

Optimasi metaheuristic adalah suatu 
metode yang dilakukan dengan memperbaiki kandidat penyelesaian secara iteratif dan efisien sesuai dengan fungsi objektifnya. Metode ini mampu menghasilkan penyelesaian yang baik untuk menemukan solusi yang optimal, dalam waktu cepat (acceptable). Artificial Bee Colony (ABC) adalah pendekatan population-based metaheuristic diusulkan oleh Karaboga yang terinsiprasi dari perilaku cerdas kawanan lebah madu mencari makanan [3][4].

Hasil penurunan rugi-rugi daya pada sistem distribusi di dapat melalui analisis simulasi optimasi pada software. Analisis terhadap rugi-rugi daya pada Penyulang Panji menggunakan Load Flow Analysis, Sedangkan untuk analisis optimasi titik interkoneksi DG pada Penyulang Panji menggunakan metode Artifificial Bee Colony (ABC) untuk mencari penempatan terbaik DG yang dipasang dengan memperhatikan parameter rugi-rugi jaringan dan tegangan sistem, sehingga dapat meminimalkan rugi-rugi daya yang terjadi pada jaringan distribusi Penyulang Panji.

\section{TINJAUN PUSTAKA}

a. Distributed Generation

DG biasanya ditempatkan pada bus yang langsung menyuplai pusat beban dan atau pada gardu induk distribusi [2]. DG memiliki fungsi utama yaitu sebagai pembangkit cadangan skala kecil yang dapat meningkatkan keandalan penyaluran tenaga listrik, dan dapat mengatasi pertumbuhan beban yang tidak pasti [5].

\section{b. Analisis Aliran Daya (Load Flow)}

Aliran daya pada sistem distribusi digunakan sebagai acuan dalam proses pemasangan DG. Persamaan analisis aliran daya merupakan suatu persamaan nonlinier yang dalam penyelesaiannya menggunakan teknik iterasi [5] [6].

Analisis aliran daya sangat penting dilakukan untuk menilai performansi dan keefektifan perubahan - perubahan yang direncanakan pada suatu sistem pada tahap perencanaan [6].

Tujuan dilakukannya analisis aliran daya adalah untuk menentukan arus, tegangan, daya reaktif atau daya aktif setiap bus pada jaringan disribusi [7].

Dalam analisis aliran daya pada setiap bus diklasifikasikan menjadi tiga [6] :

1. Bus Beban (Load Bus)

Biasanya disebut bus $P, Q$, karena besaran-besaran yang diketahui adalah $P$ dan $\mathrm{Q}$, sedangkan besaran $\mathrm{V}$ dan $\delta$ tidak diketahui.

2. Bus Kontrol (Generator Bus)

Biasanya disebut bus $P, V$, karena hanya besaran $P$ dan $V$ saja yang diketahui, sedangkan besaran $\delta$ dan $Q$ tidak diketahui.

3. Bus Ayun (Slack Bus)

Besaran yang diketahui pada slack bus adalah $\mathrm{V}$ dan $\delta$, dan biasanya $\delta$ bernilai nol $(\delta=0)$. Selama perhitungan aliran daya, besaran $\mathrm{V}$ dan $\delta$ tidak berubah (konstan).

Pada penenlitian ini, menggunakan perhitungan dengan menggunakan metode Newton-Raphson.

\section{c. Rugi-rugi Daya (Losses)}

Rugi-rugi daya adalah besarnya daya yang hilang dalam proses pengaliran daya listrik mulai dari pembangkitan sampai dengan konsumen. Terjadinya susut atau rugi rugi energi pada sistem kelistrikan merupakan salah satu acuan untuk mengetahui efesien atau tidaknya sistem kelistrikan tersebut. rugi-rugi daya yang dihasilkan dari penyulang tersebut dapat dirrepresentasikan seperti Gambar 1 berikut.

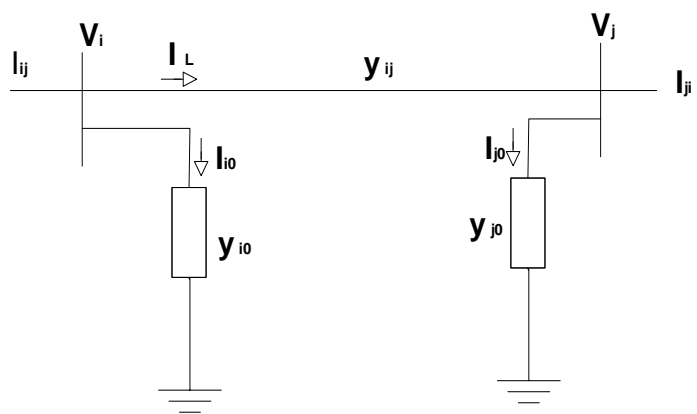

Gambar $\overline{1}$ Representasi rugi - rugi jaringan

Suatu saluran yang menghubungkan bus I dan $j$, dimana arus yang mengalir dalam saluran diperoleh dari persamaan berikut [8].

arus yang mengalir dari $i$ ke $j$

$$
I_{i j}=I_{L}+I_{i 0}=y_{i j}\left(V_{i}-V_{j}\right)+y_{i 0} V_{j}
$$

Sebaliknya, arus yang mengalir dari $j$ ke $i$ dapat dinyatakan

$$
I_{j i}=-I_{L}+I_{j 0}=y_{i j}\left(V_{j}-V_{i}\right)+y_{i 0} V_{j}
$$

Daya Semu yang terjadi pada konduktor

$$
S_{i j}=V_{i} . I_{i j} \text { atau } S_{j i}=V_{i} \cdot I_{i j}^{*}
$$

Dengan begitu, nilai rugi - rugi dari suatu jaringan distribusi didapatkan dengan menjumlahkan seluruh rugi - rugi yang diperoleh pada setiap saluran. 


$$
S_{L}=S_{i j}+S_{j i}
$$

Sehingga rugi-rugi daya yang dihasilkan dari penyulang tersebut. dapat dirumuskan sebagai berikut.

$$
P=I^{2} \cdot R
$$

Keterangan :

$I_{i j}=$ Arus yang mengalir dari $i$ ke $j$

$I_{\text {io }} \quad=$ Arus mengalir dari I awal

$y_{i j} y_{i 0}=$ Admitansi

$V_{i} V_{j}=$ Tegangan $I$ dan $j$

$I_{L} \quad=$ Arus line

Sij = Daya semu yang mengalir dari $i$ ke $j$

$S_{L} \quad=$ Daya semu line

$I=$ Arus

$\mathrm{R}=$ Reaktansi

$\mathrm{P} \quad=$ Daya aktif

Dengan melakukan optimasi interkoneksi DG maka dapat diketahui titik yang paling optimal dengan rugi - rugi daya yang minimum, sesuai dengan fungsi tujuannya.

\section{d. Metode Artficial Bee Colony}

Algoritma Artificial Bee Colony (ABC) adalah pendekatan population-based metaheuristic yang diusulkan oleh Karaboga. Algoritma $A B C$ terinsiprasi oleh perilaku cerdas kawanan lebah madu mencari makanan [9].

Pada model algoritma $A B C$ terdiri dari 3 komponen esensial, yaitu : Food Sources (sumber makanan), Employed Foragers (lebah pekerja), Unemployed Foragers (scout dan onlooker). Lebah onlooker akan menunggu di sarang untuk memilih sumber makanan dan lebah pekerja adalah lebah yang pergi ke sumber makanan. Sedangkan scout bee adalah lebah yang melakukan pencarian secara acak [10].

Setiap lebah pekerja hanya akan mencari satu sumber makanan. Saat sumber makanannya telah habis atau sudah pada nilai limit (batasan) lebah pekerja akan berubah menjadi lebah scout.

Secara umumnya, struktur dari algoritma ABC seperti Gambar 2 berikut ini [11].

Tahap Inisialisasi
Iterasi (pengulangan)
Tahap Employed bee
Tahaponlooker bee
Tahap scout bee
Mengingat solusi terbaik
Iterasi = Iterasi + 1.
Sampai Iterasi = Maksiterasi.

Gambar 2 Pseudocode Struktur Umum dari Algoritma $A B C$

\section{METODOLOGI PENELITIAN}

Optimasi titik interkoneksi DG guna meminimalkan rugi - rugi daya pada Penyulang Panji dilakukan dalam sebuah simulasi, dengan menggunakan metode artificial bee colony $(\mathrm{ABC})$ untuk menentukan tempat terbaik dalam pemasangan DG. Dalam paper ini diperlukan data-data sebagai berikut:

a. Data output daya DG (PLTM Muara)

b. Single line diagram Penyulang Panji

c. Data penghantar (panjang, resistansi, dan reaktansi)

d. Data beban puncak Penyulang Panji

e. Data Pembangkitan Penyulang Panji

Semua parameter umum dirubah menjadi parameter algoritma $A B C$, sehingga lebah dapat melakukan pencarian secara acak untuk memperoleh lokasi optimal dari penempatan DG.

Letak bus yang akan di interkoneksi dengan DG ditentukan oleh jumlah populasi lebah, dan ilai fungsi fitness mewakili nilai kerugian pada jaringan distribusi. Analogi tersebut dapat dilihat padai Tabel 1 berikut ini.

Tabel 1 Analogi metode ABC dengan Penentuan Titik Interoneksi

\begin{tabular}{|c|c|}
\hline Algoritma ABC & $\begin{array}{c}\text { Penentuan titik Inter- } \\
\text { koneksi DG }\end{array}$ \\
\hline $\begin{array}{c}\text { Posisi sumber } \\
\text { makanan }\end{array}$ & $\begin{array}{c}\text { Kandidat bus inter- } \\
\text { koneksi DG }\end{array}$ \\
\hline Sumber makanan & $\begin{array}{c}\text { Data rugi }- \text { rugi hasil in- } \\
\text { terkoneksi }\end{array}$ \\
\hline Fungsi objektif & $\min \sum P_{\text {loss }}$ \\
\hline Fungsi Fitness & $f_{\text {fitness }}=\frac{1}{1+f_{\text {objektif }}}$ \\
\hline
\end{tabular}

Scout bee akan menyebar dan melakukan pencarian sumber makanan secara acak, kemudian lebah pekerja akan menghitung setiap fitness dari sumber makanan yang ditemukan. Oonlooker akan menseleksi dan mengingat setaip perhitungan dari sumber makanan sehingga diperoleh sumber makanan terbaik dengan mendapatkan nilai rugi rugi daya yang minimum.

Analisis tersebut dapat dilihat melalui diagram alur analisis pada Gambar 3 


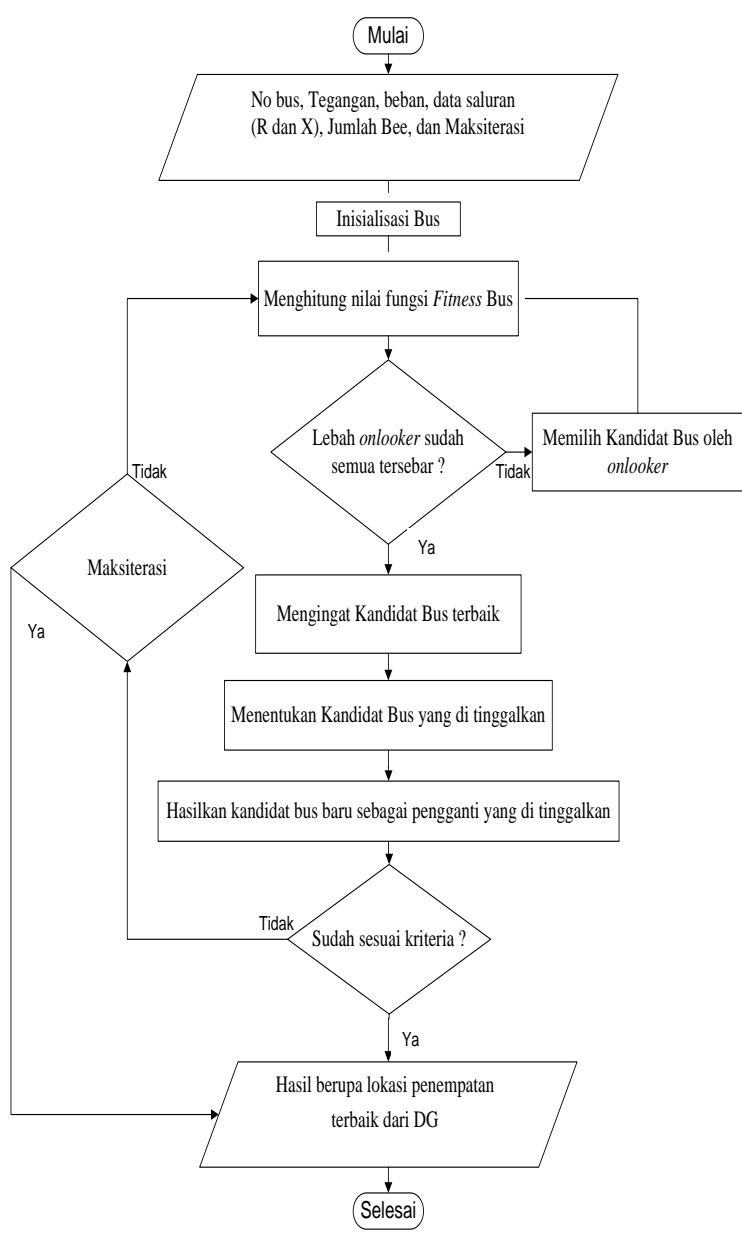

Gambar 3 Diagram Alur Program Artificial Bee Colony

\section{HASIL DAN PEMBAHASAN}

a. Data Input Pada Penyulang Panji

Penyulang Panji memiliki konfigurasi tipe radial 20 kV. Berikut Detail dan karakteristik Penyulang Panji :

\begin{tabular}{|c|c|}
\hline Base MVA & $: 100$ MVA \\
\hline Panjang Jaringan & : 64,671 kms \\
\hline Jenis Penghantar & $\begin{array}{l}\text { AAACS, AAAC, MVTIC, } \\
\text { dan NA2XSEBY }\end{array}$ \\
\hline Daya Sumber & : $2039 \mathrm{~kW}$ \\
\hline Jumlah Bus & $: 153$ \\
\hline
\end{tabular}

Data di simulasikan dengan software untuk mendapatkan nilai aliran daya dan titik optimal dari setiap kemungkinan interkoneksi DG pada jaringan distribusi Penyulang Panji.

b. Analisis Rugi - rugi Daya Awal Penyulang Panji

Analisis Load Flow dilakukan untuk menghitung kondisi awal rugi-rugi daya pada penyulang Panji dengan menggunakan metode Newton-Raphson saat kondisi awal tanpa terinterkoneksi oleh DG. Besarnya rugirugi daya yang dihasilkan pada Penyulang Panji dapat dilihat pada Tabel 2.

Tabel 2 Rugi-rugi Daya Penyulang Panji Kondisi Tanpa Terinterkoneksi DG

\begin{tabular}{|c|c|c|c|}
\hline No & Uraian & Nilai & Keterangan \\
\hline 1 & $\begin{array}{c}\text { Total Daya } \\
\text { Penghantar }\end{array}$ & $2039 \mathrm{~kW}$ & Sumber \\
\hline 2 & $\begin{array}{c}\text { Total Rugi- } \\
\text { rugi }\end{array}$ & $48,2 \mathrm{~kW}$ & $\begin{array}{c}\text { Rugi-rugi daya } \\
\text { Tanpa DG }\end{array}$ \\
\hline 3 & $\begin{array}{c}\text { Total Ru- } \\
\text { gi-rugi }\end{array}$ & $44,4 \mathrm{~kW}$ & $\begin{array}{c}\text { Rugi-rugi dengan } \\
\text { DG koneksi SK 64 }\end{array}$ \\
\hline
\end{tabular}

c. Analisis Rugi - rugi Daya Pada Penyulang Panji Menggunakan Metode Artificial Bee Colony (ABC)

Penyulang Panji memiliki sistem dstribusii yang terdiri dari 1 pembangkit dan 153 bus. Algoritma $A B C$ digunakan untuk menentukan lokasi penempatan optimal dari DG yang harus ditempatkan pada sistem untuk meminimalkan rugi-rugi daya pada penyulang Panji.

Data-data yang dipergunakkan dalam metode $A B C$ ini seperti : penomoran bus, data beban dan pembangkit, serta data parameter saluran. Berikut merupakan data parameter saluran dari Penyulang Panji yang digunakan sebagai input coding Artificial Bee Colony (ABC) seperti ditampilkan pada Tabel 3.

Tabel 3 Data R dan X Penyulang Panji

\begin{tabular}{|c|c|c|c|c|c|c|c|}
\hline $\begin{array}{l}\text { Dari } \\
\text { Bus }\end{array}$ & $\begin{array}{c}\text { Ke } \\
\text { Bus }\end{array}$ & $\begin{array}{c}\text { Tahanan } \\
\text { urutan } \\
\text { positif } \\
(\Omega / \mathrm{km})\end{array}$ & $\begin{array}{c}\text { Reaktansi } \\
\text { urutan } \\
\text { positif } \\
(\Omega / \mathrm{km})\end{array}$ & $R(\Omega)$ & $R(p, u)$ & $X(\Omega)$ & $X(p . u)$ \\
\hline 1 & 2 & 0.162 & 0.11995 & 0.01782 & 0.00445 & 0.01319 & 0.00329 \\
\hline 2 & 3 & 0.265 & 0.13000 & 0.68290 & 0.17073 & 0.33499 & 0.08357 \\
\hline 3 & 4 & 0.2162 & 0.3305 & 0.05253 & 0.00045 & 0.08031 & 0.00061 \\
\hline 4 & 5 & 0.2162 & 0.3305 & 0.00043 & 0.00060 & 0.00066 & 0.00081 \\
\hline 5 & 6 & 0.2162 & 0.3305 & 0.01102 & 0.00098 & 0.01685 & 0.00132 \\
\hline 6 & 7 & 0.2162 & 0.3305 & 0.09837 & 0.00108 & 0.15037 & 0.00145 \\
\hline 7 & 8 & 0.2162 & 0.3305 & 0.00043 & 0.00007 & 0.00066 & 0.00004 \\
\hline 8 & 9 & 0.2162 & 0.3305 & 0.09058 & 0.00043 & 0.13847 & 0.00026 \\
\hline 9 & 10 & 0.2162 & 0.3305 & 0.02075 & 0.00100 & 0.03172 & 0.00134 \\
\hline 10 & 11 & 0.2162 & 0.3305 & 0.00043 & 0.00046 & 0.00066 & 0.00062 \\
\hline & $\cdots$ & & & & & & \\
\hline 152 & 153 & 0.2162 & 0.3305 & 0.00043 & 0.00006 & 0.00066 & 0.00009 \\
\hline
\end{tabular}

Tujuan dari optimasi ini untuk mengetahui titik yang paling optimal penyambungan antara DG ke grid. Dengan melakukan optimalisasi penyambungan DG maka dapat diketahui rugi - rugi daya yang paling mini- 
mum, sesuai dengan fungsi tujuannya $\min \sum$ Ploss $=\min \left(\mathrm{I}^{2} . \mathrm{R}\right)$

Kawanan lebah ini akan menyebar untuk mencari kandidat bus secara acak. Kemudian akan ditemukan kandidat bus baru, lebah akan menghitung nektar (fitness) dari setiap kandidat bus yang ditemukan.

\section{d. Running Program}

Setelah melakukan coding program maka akan dilanjutkan dengan proses running menggunakan bantuan GUI (Graphical User Interface) seperti pada Gambar 4.

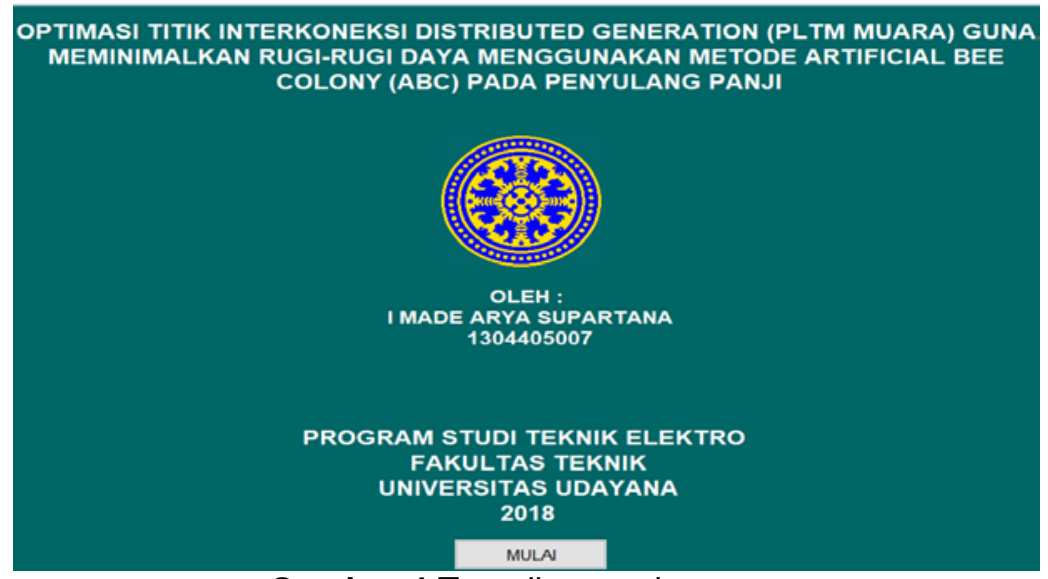

Gambar 4 Tampilan awal program

Tampilan awal program GUI menampilkan menu Judul, data diri, dan menu "MULAl" yang dapat di klik untuk menampilkan data pada layer berikutnya.Total rugi-rugi daya dari 153 bus yang terdapat pada Penyulang Panji adalah sebesar 48,298 kW. Selanjutnya data akan diproses untuk mencari lokasi ter- baik interkoneksi DG sehingga dapat mengurangi rugi-rugi daya aktif. Tampilan rugi daya setelah optimasi dapat dilihat pada Gambar 5

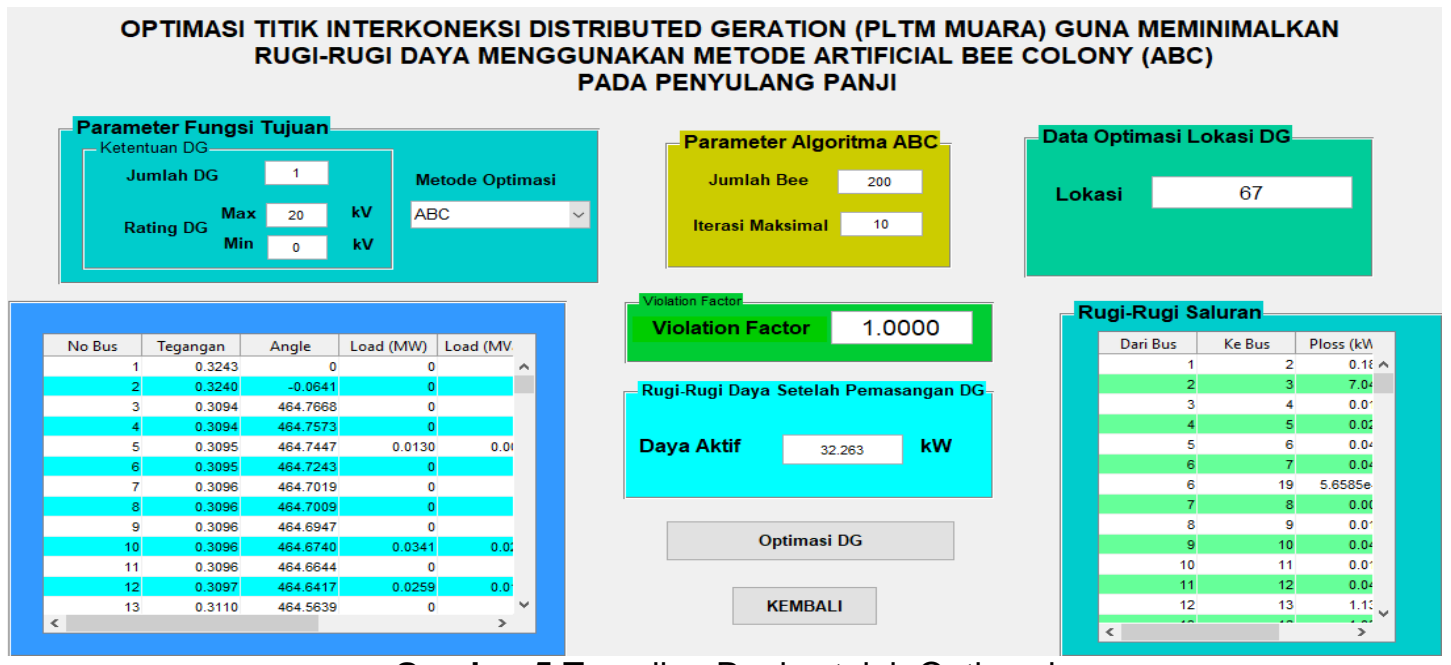

Gambar 5 Tampilan Rugi setelah Optimasi

Diperoleh hasil titik terbaik untuk interkoneksi Distributed Generation (DG) setelah dilakukan optimasi pada Penyulang Panji terdapat pada bus 67 (SK099) dengan rugirugi daya sebesar $32,263 \mathrm{~kW}$.

Karakteristik Artificial Bee Colony (ABC) dalam program ini bersifat hanya mencari nilai rugi daya terkecil. Lebah $A B C$ selalu berpencar secara acak dan menghasilkan beberapa lokasi DG yang nantinya akan dipiih satu lokasi terbaik dalam menentukan satu nilai tujuan (losses terkecil). Keberhasilan metode Artificial Bee Colony (ABC) untuk menyelesaikan optimasi menurunkan rugi rugi daya pada Penyulang Panji ditunjukan Tabel 4. 
Tabel 4 Rugi-rugi daya sebelum dan sesudah Interkoneksi DG

\begin{tabular}{|c|c|c|}
\hline No & Uraian & Nilai \\
\hline 1 & $\begin{array}{c}\text { Rugi Daya Sebelum } \\
\text { koneksi DG }\end{array}$ & $48,298 \mathrm{~kW}$ \\
\hline 2 & $\begin{array}{c}\text { Rugi Daya koneksi DG } \\
\text { di SK 64 }\end{array}$ & $44,4 \mathrm{~kW}$ \\
\hline 3 & $\begin{array}{c}\text { Rugi Daya Setelah Op- } \\
\text { timasi Interoneksi DG }\end{array}$ & $32,263 \mathrm{~kW}$ \\
\hline \multicolumn{2}{|c|}{ Selisih Rugi-rugi Daya } & $\mathbf{1 6 , 0 3 5} \mathbf{k W}$ \\
\hline
\end{tabular}

Perbandingan nilai rugi - rugi daya pada Penyulang Panji Sebelum dan sesudah interkoneksi DG dapat dilihat pada gambar 6 .

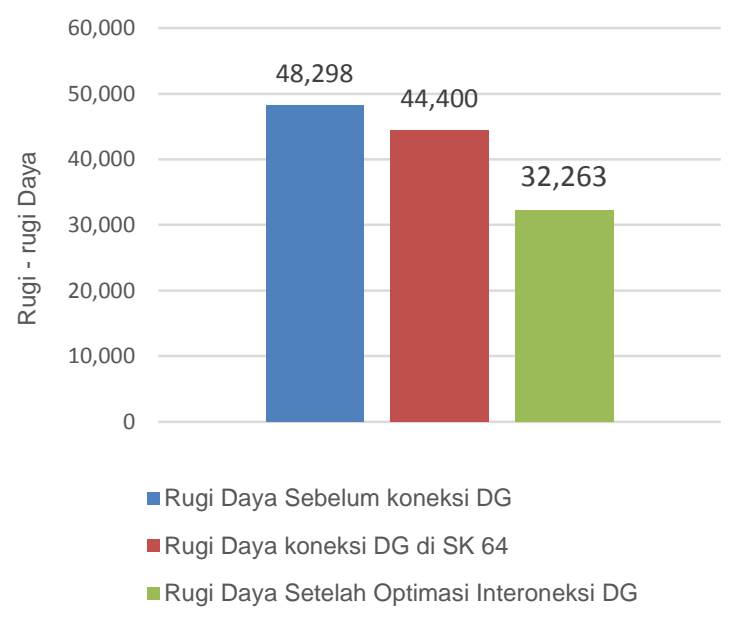

Gambar 6 Perbandingan rugi-rugi daya pada Penyulang Panji

Kondisi sebelum interkoneksi DG didapat niali rugi - rugi daya sebesar 48,298 kW, dan saat interkoneksi pada titik SK064 atau pada Bus 100 nilai rugi-rugi daya menjadi sebesar 44,4 kW. Sedangkan hasil simulasi optimasi titik interkoneksi terbaik terdapat pada Bus 67 atau gardu SK099, dengan rugi-rugi daya sebesar 32,263 kW.Selisih penurunan rugirugi daya sebelum dan sesudah interkoneksi DG adalah sebesar 16,035 kW. Terjadi penurunan rugi - rugi daya sebesar 33,2\% dari rugi sebelumnya.

\section{SIMPULAN}

Berdasarkan hasil analisis dan pembahasan untuk optimasi titik interkoneksi Distributed Generation guna meminimalkan rugi - rugi daya menggunakan metode Artificial Bee Colony (ABC) pada Penyulang Panji, maka dapat ditarik simpulan melalui teknik optimasi didapatkan lokasi interkoneksi DG yang paling optimum dengan mereduksi rugi
- rugi daya sebesar 33,2\% (kondisi awal 48,2 kW menjadi 32,263 kW),

\section{DAFTAR PUSTAKA}

[1] Sunanda, Wahri. 2013. Perbaikan Keandalan Sistem Melalui Pemasangan Distributed Generation. Bangka Belitung: Jurnal IImiah Foristek Vol.3, No.2. Universitas Bangka Belitung.

[2] Muljono A.B., Nrartha, Ari I Md. 2009. Analisis Pengaruh Unit Pembangkit Tersebar Terhadap Stabilitas Dinamis Sistem Tenaga. Mataram: Jurnal Teknologi Elektro Vol. 8, No. 1. Universitas Mataram.

[3] Gunantara, N., \& Dharma, A. 2017. Optimal path pair routes through multicriteria weights in ad hoc network using genetic algorithm. International Journal of Communication Networks and Information Security (IJCNIS), 9(1).

[4] Gunantara, N., Sudiarta, P. K., \& Antara, I. N. G. 2018. Multi-criteria weights on ad Hoc networks using particle swarm optimization for optimal path pairs. International Review of Electrical Engineering (IREE),13(1),

15. doi:10.15866/iree.v13i1.14082

[5] Gusmara, N. 2015. Analisis Pengaruh Interkoneksi Distributed Generation (PLTSA Suwung) Terhadap Rugi-Rugi Daya Dan Keandalan Pada Penyulang Serangan. Bukit Jimbaran: Skripsi. Jurusan Teknik Elektro, Universitas Udayana.

[6] Dion, A.P. 2015. Analisa Rugi Daya Pada Penyulang Bangli Dengan Beroperasinya PLTS Kayubihi. Bukit Jimbaran: Skripsi. Jurusan Teknik Elektro Fakultas Teknik Universitas Udayana.

[7] Sulasno. 1993. Analisis Sistem Tenaga. Semarang: Badan Penerbit Universitas Diponegoro

[8] Saadat, H. in Power System Analysis, New York, McGraw-Hill Companies, 1999.

[9] Karaboga.Dkk.2009. A comparativestudy of Artificial Bee Colony algorithm. Erciyes University, The Department of Computer Engineering, Melikgazi, 38039 Kayseri, Turkey.

[10] Rakhmad. 2015. Penerapan Algoritma Artificial Bee Colony dalam Aplikasi Penjadwalan Pelajaran untuk Sekolah Menengah Pertama. Jurusan S1 Teknik Informatika Fakultas Teknologi Informasi, Universitas Kristen Maranatha.

[11] Lutfhi. 2013. Optimasi Penempatan Distributed Generation Pada IEEE 30 Bus System Menggunakan Bee Colony 
Algorithm. Jurusan Teknik Elektro, Universitas Diponegoro Semarang 